\title{
Microarray analysis of differentially expressed gene responses to bisphenol A in Arabidopsis
}

\author{
Yong-Sheng Tian ${ }^{1,2^{*}}$, Xiao-Fen Jin ${ }^{1 *}$, Xiao-Yan Fu', Wei Zhao', Hong-Juan Han ${ }^{1}$, Bo Zhu', \\ Man-Liu² and Quan-Hong Yao'
}

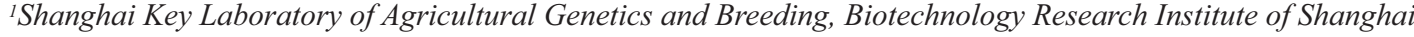 \\ Academy of Agricultural Sciences, Shanghai, 201106, China \\ ${ }_{2}^{2}$ Shanghai Ruifeng Agricultural Science and Technology Co., Ltd, Shanghai, 201106, China
}

(Received April 11, 2014; Accepted June 20, 2014)

\begin{abstract}
Environmental levels of bisphenol A (BPA) are a global concern because the compound can cause damage to reproductive organs, the thyroid gland, and brain tissues at developmental stages. Plants are important in removing BPA from the atmosphere, soil, and water. However, knowledge on the mechanism by which plants respond to this compound is limited. To determine the response mechanism of plants to BPA, we used a microarray system to analyze the gene expression patterns of Arabidopsis thaliana after irrigation with $3.0 \mathrm{mM}$ BPA. We identified 651 genes that were differentially expressed upregulated and 470 genes that were downregulated by BPA. These genes may specifically contribute to BPA uptake, transformation, conjugation, and compartmentation in plants. The potential function of upregulated genes in plant defense against BPA was also determined.
\end{abstract}

Key words: Arabidopsis, Microarray, RT-PCR, BPA, Toxicity

\section{INTRODUCTION}

Bisphenol A \{BPA; 4-[2-(4-hydroxyphenyl)propan-2$\mathrm{yl}]\}$ is an industrially important compound widely used for the production of polycarbonates and other plastics (Ben-Jonathan and Steinmetz, 1998). Over the past few years, many issues have been raised all over the world regarding the use of BPA. BPA possesses estrogenic activities; hence, this compound mimics the function of estrogen upon entering living systems. BPA has been placed in the category of compounds called endocrine disruptors. The compound can cause damage to reproductive organs, the thyroid gland, and brain tissues at developmental stages and has been linked to cancer development in humans (Welshons et al., 2006).

Human exposure to BPA occurs mainly through the diet. BPA molecules are linked through ester bonds to produce polycarbonate plastics, which are used in the manufacture of plastic containers. These ester bonds undergo hydrolysis under high temperature, such as when food stored in plastic containers is microwaved, and $\mathrm{pH}$ conditions, such as when acidic or basic food is stored in plastic containers for long durations, causing leaching out of BPA (Welshons et al., 2006). BPA then mixes with the food or beverage stored in the plastic container, and consumption of the food stored in the container results in BPA exposure (Krishnan et al., 1993).

A significant quantity of waste containing BPA is generated from plastic manufacturing facilities. This waste is discharged into water bodies (Ye et al., 2009) and finally settles in lakes or rivers, causing accumulation of BPA on the surface of the water. The compound can cause severe and adverse effects on human lives (Hu et al., 2013). Several studies have focused on biodegradation of BPA, and recent research indicates that fungi and bacteria are efficient in degrading this compound (Hirano et al., 2000; Tsutsumi et al., 2001; Fukuda et al., 2001). However, the use of bacteria to degrade BPA in polluted sites may cause adverse ecological impacts caused by unlimited propagation.

Phytoremediation is a useful method for removing BPA pollutants (Lindholst et al., 2001); using this system, plants can grow independently using sunlight, water, and inorganic ions and be cultivated through seed germination

\footnotetext{
Correspondence: Man-Liu (E-mail: romance727@foxmail.com)

Quan-Hong Yao (E-mail: yaoquanhong_sh@yahoo.com.cn)

*These authors equally contributed to this work.
} 
or vegetative propagation, causing minimal disturbance to contaminated sites. However, plant genes responsible for BPA uptake, degradation, and conjugation remain unknown. The mechanisms of BPA toxicity to plants are also poorly understood. As molecular-level research on the plants stress response and defense mechanisms to BPA has rarely been reported, elucidating plant transcriptional responses to BPA is necessary and useful for determining appropriate phytoremediators for the compound. In the present study, we investigated transcriptional changes in Arabidopsis in response to BPA using microarray analysis. Several BPA-induced and BPA-repressed genes were identified, and the potential function of upregulated genes in plant defense against BPA was discussed.

\section{MATERIALS AND METHODS}

\section{Arabidopsis culture conditions and BPA response}

The Arabidopsis thaliana cv. Columbia seeds were surface sterilized and spread on solid Murashige and Skoog (MS) medium supplemented with 3\% sucrose. To investigate Arabidopsis response to BPA, BPA was added into each plate of solid MS medium, with the concentration of $0,100,200,300$ and $500 \mu \mathrm{M}$. Acetone was added into the control plate $(0 \mathrm{mg} / \mathrm{L}$ BPA concentration) for eliminating the inequality caused by solvent. After jarovization at $4^{\circ} \mathrm{C}$ for $2 \mathrm{~d}$, the plates were placed vertically in a greenhouse kept at $22^{\circ} \mathrm{C}$ under $16 \mathrm{hr}$ light $/ 8 \mathrm{hr}$ dark. The growth responses to BPA were analyzed by measuring the primary root length after growth for $12 \mathrm{~d}$. The Arabidopsis seedlings were also grown in pots containing a mixture of vermiculite, peat moss, and perlite $(18: 6: 1 \mathrm{v} / \mathrm{v})$. The 4-week-old seedlings were exposed to $0,1,2$ and $3 \mathrm{mM}$ BPA. For avoiding BPA volatilization, we poured the same volume $(200 \mathrm{ml})$ of different concentrations of BPA into the plastic bag, put the pot with seedlings into the liquor, and then used elastic string to bundle the bag and pot together. One month later, the growth status was observed.

\section{RNA preparation}

Using microarray to study the genes related to BPA, 4-week-old seedlings were irrigated with $3 \mathrm{mM}$ BPA for $24 \mathrm{hr}$ and harvested. Acetone-treated-seedlings serve as control for eliminating the inequality caused by solvent. Plants were treated during the light period, and three replications with 12 plants in each were included. After treatments, all 12 plants in a pot were harvested and mixed, immediately frozen in liquid nitrogen, and stored at $-70^{\circ} \mathrm{C}$ for RNA isolation. Total RNA from pooled plants was isolated and purified using Trizol reagent (Invitrogen, Carlsbad, CA, USA). RNA quality was assessed by agarose gel electrophoresis for two-color microarrays and by Agilent Bioanalyzer for gene expression microarrays.

\section{Microarray experiment}

Microarray analyses were carried out using a competitive hybridization method (i.e. dye-flip method) using the Agilent microarray system (Agilent Technologies, Palo Alto, CA, USA). All procedures were carried out according to the manufacturer's protocols. Briefly, $2 \mu \mathrm{g}$ of total RNA from each sample was used to synthesize cRNA and was labeled with cyanine-3 (Cy3)-labeled CTP (Perkin Elmer/NEN Life Sciences, Tokyo, Japan). The labeled cRNAs (including a treatment and a control sample) were competitively hybridized to the Agilent Arabidopsis (V4) gene expression microarray $(4 \mathrm{x} 44 \mathrm{~K})$, and then washed. The hybridized slides were scanned using Agilent DNA Microarray Scanner and data points were extracted using Agilent Feature Extraction software. Expression profile trends for the selected genes were examined by reverse transcription-polymerase chain reaction (RT-PCR) using specific primers.

\section{Data analysis}

The hybridization signals were quantified and analysed using Agilent Feature Extraction software (Agilent Technologies, Inc.). Statistical analysis was performed using Cluster 3.0 software (University of Tokyo). In brief, those transcripts that had detection call ' $\mathrm{P}$ ', signal value $\geq 25$ and change $\mathrm{P}$ value $<0.05$ in all the three replicates of each treatment were selected in the identification of BPA relative genes. Only the transcripts with a minimum twofold increase or decrease in signal over the control in at least two of the three biological replicates and a coefficient of variation $(\mathrm{CV})<10 \%$ were identified as BPA relative genes. The signal log ratio is the change in the expression level of a transcript between the control and experimental. samples, expressed as the $\log 2$ ratio. The fold change was calculated as 2 (signal log ratio) when the signal $\log$ ratio was $\geq 0$.

\section{RT-PCR for validity of the microarray date}

Gene-specific primers were synthesized for selected probe sets, and RT-PCR was carried out to verify the microarray results (Primers are listed in Supplementary Table S1). $3 \mathrm{mM}$ BPA solution was used to treat the one-month-old seedlings for 12, 24 and $48 \mathrm{hr}$. Total RNA from Arabidopsis treated with different time was extracted by using the Trizol Kit (Watson biotechnology Inc., New Taipe, Taiwan). DNase I (Promega, Msdison, 
WI, USA) was used to remove the genomic DNA contamination. The first strand of cDNA was synthesized by using $2 \mu \mathrm{g}$ total RNA as template with Reverse Transcription System (TOYOBO, Osaka, Japan) in a $20 \mu \mathrm{l}$ reaction volume. The Arabidopsis actin gene ACT2 (GenBank No. U41998) was used as the internal standard. PCR conditions were as follows: $94^{\circ} \mathrm{C}$ for $5 \mathrm{~min}$, different cycles of $94^{\circ} \mathrm{C}$ for $20 \mathrm{sec}, 54^{\circ} \mathrm{C}$ for $20 \mathrm{sec}, 72^{\circ} \mathrm{C}$ for $30 \mathrm{sec}$, and with a final extension at $72^{\circ} \mathrm{C}$ for $10 \mathrm{~min}$. DNA intensity ratio of the target genes to $A C T 2$ was analyzed with Shine Tech Gel Analyze (Shanghai Shine Science of Technology Co. Ltd., Shanghai, China). The same results were obtained for three independent experiments, only the result from one experiment is presented. Real-time PCR was performed in a Mini Option Real-time PCR System (Bio-Rad, Hercules, CA, USA). The reaction mix $(10 \mu \mathrm{l})$ contained cDNA from $20 \mathrm{ng}$ total RNA (3 mM BPA-treated for $24 \mathrm{hr}$ ), $0.2 \mu \mathrm{M}$ of each primer, $0.2 \mu \mathrm{M}$ SYBR, $3 \mathrm{mM} \mathrm{MgCl} 2,200 \mu \mathrm{M}$ dATP, dCTP and dGTP, $400 \mu \mathrm{M}$ dUTP, 1 unit Taq DNA polymerase. Fold change in the expression of RNA was estimated using threshold cycles. All analyses were analyzed in triplicate. Mean values were calculated for relative expression ratios.

\section{RESULTS AND DISCUSSION}

\section{Growth of Arabidopsis under BPA treatment}

To investigate the toxicity of BPA to Arabidopsis, we sterilized seeds with chlorinated lime and then sowed them in MS solid medium containing 0, 100, 200, 300, and $500 \mu \mathrm{M}$ BPA. Seed growth after $10 \mathrm{~d}$ is shown in Fig. 1A. All BPA concentrations affected the growth of treated seeds compared with that of the control $(0 \mu \mathrm{M}$ BPA). At 100 and $200 \mu \mathrm{M}$ BPA, seedling cotyledons turned yellow. At $300 \mu \mathrm{m}$ BPA, seed germination was gradually restricted. At $500 \mu \mathrm{m}$ BPA, seed germination was seriously restricted. To determine root growth in BPA-containing plates, we added different concentrations of BPA to the MS solid medium. The plates with Arabidopsis seeds were then positioned vertically. After $10 \mathrm{~d}$ of growth, the root length of seedlings at each concentration was recorded; relevant results are illustrated in Figs.

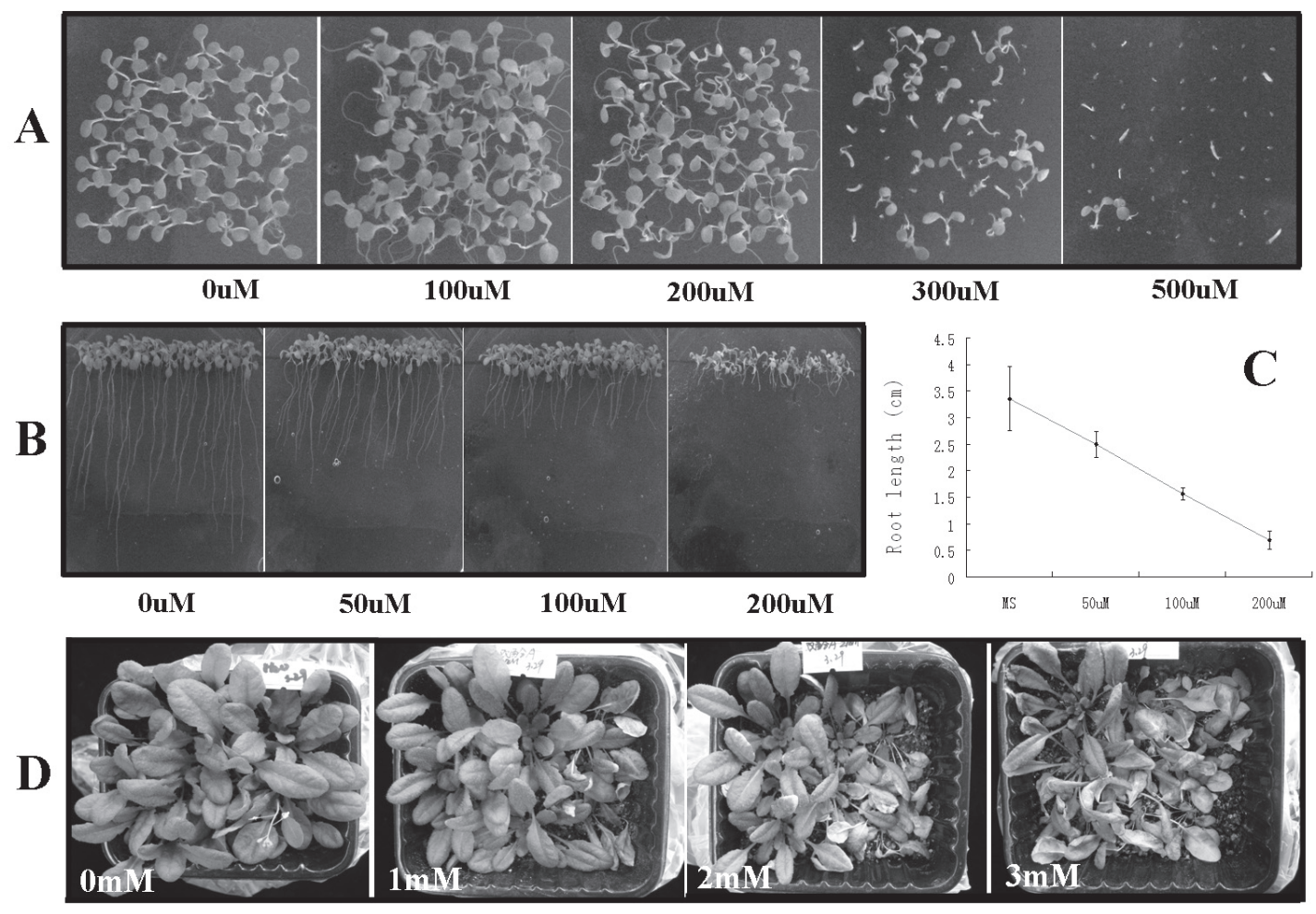

Fig. 1. Effect of BPA treatment on Arabidopsis seedling growth. A) Seedling growth. Seeds were sowed on 0, 100, 200, 300 or 500 $\mu \mathrm{M}$ BPA plates. The pictures were captured after $10 \mathrm{~d}$ growth. B) Root growth on BPA containing plates. The pictures were captured after $10 \mathrm{~d}$ growth. C) Root length was measured after $10 \mathrm{~d}$ growth. The bars represent the standard deviation of one experiment, $n>=35$. D) One-month-old plants respond to BPA. One-month-old plants grew in soil were irrigated with $0,1,2,3 \mathrm{mM}$ BPA solution. The picture was captured after $7 \mathrm{~d}$ treatment. 
$1 \mathrm{~B}$ and $1 \mathrm{C}$. The average root length of seedlings grown on the control plate was $3.4 \mathrm{~cm}$; by contrast, root lengths of $2.5,1.6$, and $0.7 \mathrm{~cm}$ were observed in seedlings grown on plates with 50,100 , and $200 \mu \mathrm{M}$ BPA, respectively. The corresponding phenomenon was observed in seedlings grown in soil (Fig. 1D). To determine the relative biomass of pot-grown seedlings, we selected 1, 2, and $3 \mathrm{mM}$ BPA solutions for treatment. After $7 \mathrm{~d}$, the leaves of seedlings treated with BPA became yellow. More evident toxicosis was observed with increasing BPA concentration. On the basis of the growth of 4-week-old seedlings (Fig. 1D), we considered $3.0 \mathrm{mM} \mathrm{BPA}$ as the sub-lethal concentration and used this concentration for subsequent microarray experiments.

\section{RT-PCR to validate the microarray data}

Eighteen genes were selected to validate the microarray data using RT-PCR. The expression patterns obtained through RT-PCR were consistent with those obtained from microarray analysis (Fig. 2). RT-PCR indicated that the CTF2B in the "upregulated gene" group (Supplementary Table S2) evidently increased after BPA treatment; by contrast, PIP1A in the "downregulated gene" group (Supplementary Table S3) was extremely inhibited after BPA treatment.

Eight (fold-change $>5.0$ in expression) of the eighteen genes were further verified using real-time PCR. The average fold-change of all transcripts analyzed through real-time PCR was higher than that obtained from the microarray data (Fig. 3).

\section{Arabidopsis gene response to BPA}

An Arabidopsis (V4) gene expression microarray (4X44K) containing probes for the Arabidopsis genome was used to identify transcriptome differences in response to BPA. "P" detection and a minimum fold-change of 3 were applied. A total of 651 and 470 genes were considered up- and downregulated, respectively (Supplementary
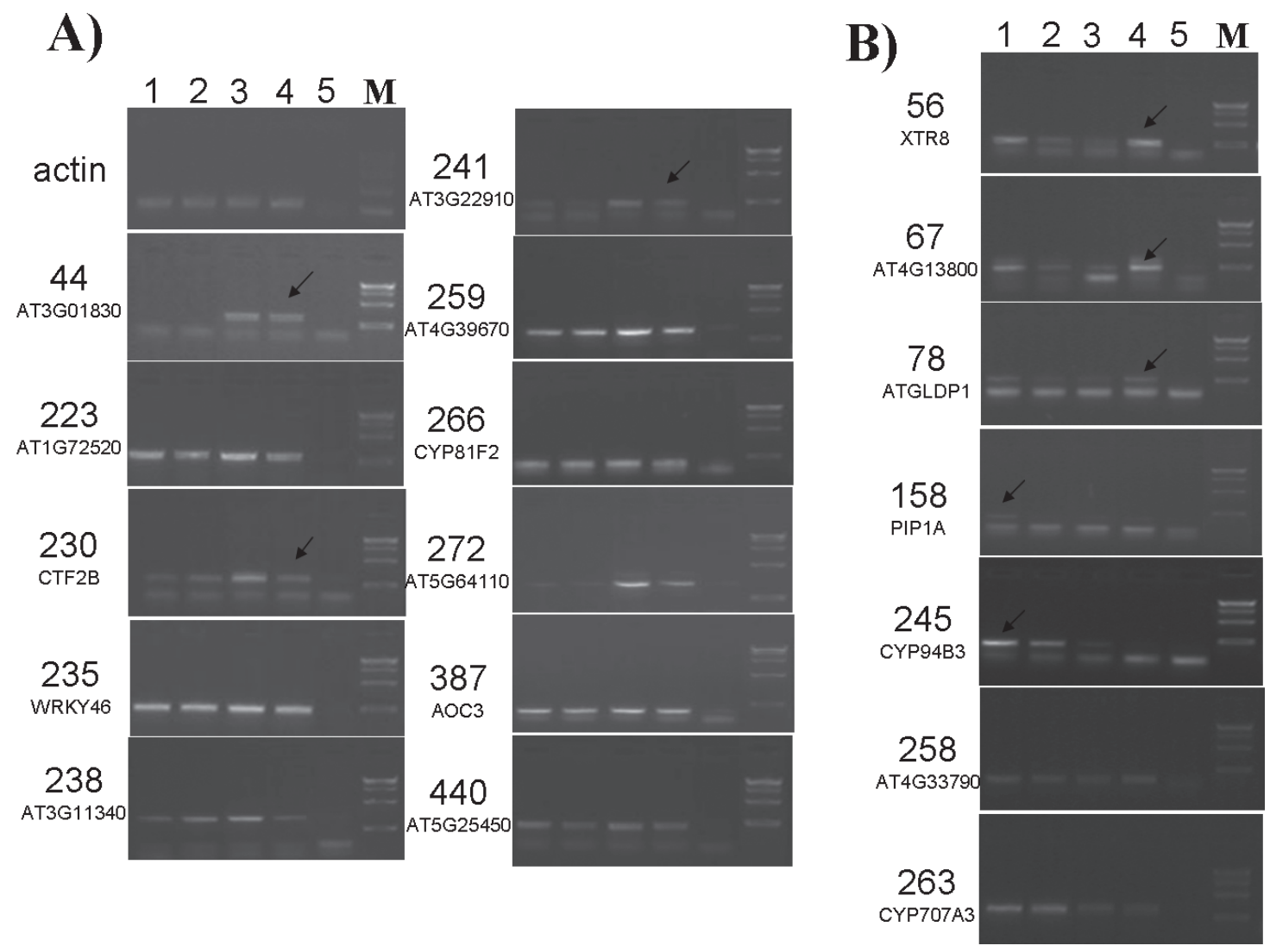

Fig. 2. Reverse transcriptase polymerase chain reaction (RT-PCR) analyses of changes in gene expression in response to BPA. Arabidopsis plants were treated with $3 \mathrm{mM} \mathrm{BPA}$ for 12, 24 and $48 \mathrm{hr}$. A, up-regulated gene; B, down-regulated gene; 1,WT; 2, $12 \mathrm{hr}$; 3, $24 \mathrm{hr} ; 4,48 \mathrm{hr} ; 5$, negative control $\left(\mathrm{H}_{2} \mathrm{O}\right)$. 
Microarray analysis of genes responses to BPA

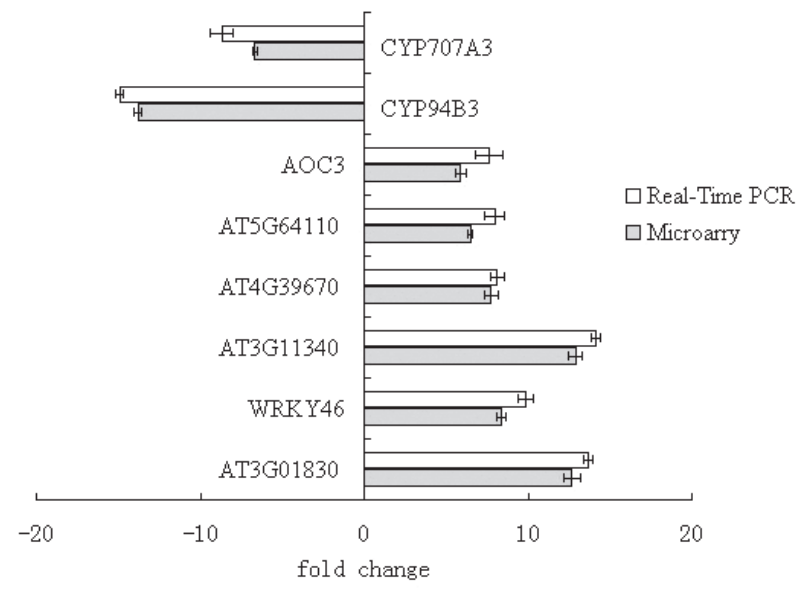

Fig. 3. Comparison of eight genes (fold change $>5.0$ in expression) expression data from microarray hybridization and real-time PCR. Changes in gene expression were estimated as the fold-change over the control. The genes tested are indicated below each group of bars. The bars represent the average fold-change and standard error in transcript changes estimated from three biological replications for both real-time PCR and microarray hybridization.

Tables S2 and S3).

BPA-up- or downregulated genes were categorized according to their biological functions (Tables 1 and 2, Fig. 4). Results strikingly featured downregulation of photosynthesis-related mRNA levels (Supplementary Table S3). Moreover, photosynthesis, chlorophyll, and proteins targeting chloroplasts decreased (Supplementary Table S3). BPA-induced downregulation of other metabolic processes stimulated senescence and programmed cell death. Peroxidase increased by 5.3-fold; this enzyme can activate cell death in response to pathogen invasion and xenobiotic uptake (Blokhina and Fagerstedt, 2010).

Cysteine protease (AT3G49340) was upregulated by BPA by about fourfold relative to the control. Cysteine proteases perform several functions in plant physiology and development, including mediation of senescence and programmed cell death (Coupe et al., 2003). Ubiquitin-protein ligase (AT2G35000), which also performs a prominent function in the control of apoptosis by conjugating and committing proteins for breakdown (Brancolini, 2008), was upregulated by 3.9-fold in the present study. During phosphate transport in the phloem between the shoots and roots, ubiquitin-protein ligase induces cell death by destroying the phosphate transporter and preventing phosphate accumulation in the cell (Lin et al., 2008).
Strong over-representation of genes involved in detoxification systems was observed among the differentially expressed transcripts (Table 1). Glutathione transferases (GSTs) and UDP-glucoronosyl/UDP-glucosyl transferases (UGTs) are important enzymes responsible for the degradation of toxic pollutants, such as polycyclic aromatic hydrocarbons and BPA (Nakajima et al., 2002; Dixit et al., 2011). GSTs tagging xenobiotics with glutathione for transport into vacuoles (Marrs, 1996; Wagner et al., 2002) were upregulated in the present study. For instance, GST-AtGSTF6 was strongly upregulated by BPA. Microarray probes recognizing AtGSTF7 and AtGSTU4 also indicated 2.5-fold increases in these transcripts induced by BPA. Similar to GSTs, UGTs perform important functions in the detoxification of endogenous and xenobiotic compounds. UGTs transfer carbohydrate residues into hydrophilic compounds containing an available nucleophilic center, such as hydroxyl, carboxyl, amino, or thiol groups, to regulate their activity, toxicity, or amenability for transport (Owens et al., 2005). In the present study, genes of UGT1 and UGT73d1 were strongly upregulated by BPA.

A previous study showed that BPA induces production of various reactive oxygen species (ROS), including highly reactive hydroxy radicals (Ooe et al., 2005). ROS function as bridges for triggering defense responses in plants (Vranova et al., 2002; Mittler et al., 2004; Laloi et al., 2001). The defense system in various subcellular compartments forms an integrated network with extensive crosstalk that can be triggered by ROS. Several genetic studies have recently revealed that plant NADPH oxidases perform important functions in ROS formation (Kwak et al., 2003; Li and Shah, 2003; Boldogh et al., 2005). The NADPH oxidase AT4G11230, a systemic signal, was upregulated by BPA in the present study. Positive feedback amplification of the signal may occur through calcium binding and promote ROS production after BPA treatment for long durations. Phosphorylation of residues located at the N-terminal region of NADPH oxidases by calcium-dependent protein kinases (CDPKs) contributes to signal amplification. Intracellular free calcium is decoded by different types of CDPKs, CDPK-related kinases, and CBL-interacting protein kinases (CIPKs, also called snf1-related kinase) (Kobayashi et al., 2007). In the present study, three CDPKs (CPK34, CPK18, and 29) and two CIPKs (CIPK1 and CIPK22) were transcriptionally activated by BPA to amplify signals for generating ROS.

BPA induced the expression of a large number of genes encoding transcription factors. Some of these genes are members of the WRKY family. For example, WRKY50, 
Y.-S. Tian et al.

Table 1. List of biological function of up-regulated genes in response to BPA

\begin{tabular}{|c|c|c|c|}
\hline Name & Hits & Total & Percent \\
\hline molecular_function & 609 & 29448 & $2.07 \%$ \\
\hline catalytic activity & 231 & 8137 & $2.84 \%$ \\
\hline cyclase activity & 1 & 15 & $6.67 \%$ \\
\hline oxidoreductase activity & 38 & 1420 & $2.68 \%$ \\
\hline transferase activity & 104 & 2722 & $3.82 \%$ \\
\hline hydrolase activity & 64 & 2933 & $2.18 \%$ \\
\hline lyase activity & 3 & 333 & $0.90 \%$ \\
\hline isomerase activity & 9 & 220 & $4.09 \%$ \\
\hline ligase activity & 15 & 453 & $3.31 \%$ \\
\hline structural molecule activity & 1 & 501 & $0.20 \%$ \\
\hline structural constituent of eye lens & 1 & 1 & $100.00 \%$ \\
\hline transporter activity & 32 & 1222 & $2.62 \%$ \\
\hline drug transporter activity & 3 & 67 & $4.48 \%$ \\
\hline transmembrane transporter activity & 27 & 930 & $2.90 \%$ \\
\hline substrate-specific transporter activity & 25 & 865 & $2.89 \%$ \\
\hline binding & 278 & 10009 & $2.78 \%$ \\
\hline nucleotide binding & 66 & 2177 & $3.03 \%$ \\
\hline pattern binding & 2 & 17 & $11.76 \%$ \\
\hline nucleic acid binding & 51 & 3939 & $1.29 \%$ \\
\hline protein binding & 100 & 2640 & $3.79 \%$ \\
\hline drug binding & 1 & 24 & $4.17 \%$ \\
\hline lipid binding & 10 & 267 & $3.75 \%$ \\
\hline oxygen binding & 5 & 231 & $2.16 \%$ \\
\hline vitamin binding & 1 & 63 & $1.59 \%$ \\
\hline carbohydrate binding & 11 & 153 & $7.19 \%$ \\
\hline peptide binding & 1 & 28 & $3.57 \%$ \\
\hline ion binding & 78 & 2255 & $3.46 \%$ \\
\hline tetrapyrrole binding & 6 & 320 & $1.88 \%$ \\
\hline cofactor binding & 13 & 264 & $4.92 \%$ \\
\hline electron carrier activity & 17 & 495 & $3.43 \%$ \\
\hline antioxidant activity & 5 & 126 & $3.97 \%$ \\
\hline peroxidase activity & 5 & 109 & $4.59 \%$ \\
\hline enzyme regulator activity & 6 & 342 & $1.75 \%$ \\
\hline enzyme inhibitor activity & 5 & 174 & $2.87 \%$ \\
\hline enzyme activator activity & 1 & 74 & $1.35 \%$ \\
\hline transcription regulator activity & 48 & 1885 & $2.55 \%$ \\
\hline transcription factor activity & 48 & 1677 & $2.86 \%$ \\
\hline transcription cofactor activity & 1 & 28 & $3.57 \%$ \\
\hline transcription activator activity & 3 & 134 & $2.24 \%$ \\
\hline transcription repressor activity & 1 & 48 & $2.08 \%$ \\
\hline protein tag & 1 & 4 & $25.00 \%$ \\
\hline nutrient reservoir activity & 2 & 58 & $3.45 \%$ \\
\hline molecular transducer activity & 24 & 375 & $6.40 \%$ \\
\hline signal transducer activity & 24 & 375 & $6.40 \%$ \\
\hline
\end{tabular}

Vol. 39 No. 4 
Microarray analysis of genes responses to BPA

Table 2. List of biological function of down-regulated genes in response to BPA

\begin{tabular}{|c|c|c|c|}
\hline Name & Hits & Total & Percent \\
\hline molecular_function & 433 & 29448 & $1.47 \%$ \\
\hline catalytic activity & 216 & 8137 & $2.65 \%$ \\
\hline cyclase activity & 2 & 15 & $13.33 \%$ \\
\hline oxidoreductase activity & 67 & 1420 & $4.72 \%$ \\
\hline transferase activity & 48 & 2722 & $1.76 \%$ \\
\hline hydrolase activity & 77 & 2933 & $2.63 \%$ \\
\hline lyase activity & 12 & 333 & $3.60 \%$ \\
\hline isomerase activity & 7 & 220 & $3.18 \%$ \\
\hline ligase activity & 6 & 453 & $1.32 \%$ \\
\hline structural molecule activity & 1 & 501 & $0.20 \%$ \\
\hline structural constituent of cell wall & 1 & 39 & $2.56 \%$ \\
\hline transporter activity & 19 & 1222 & $1.55 \%$ \\
\hline drug transporter activity & 3 & 67 & $4.48 \%$ \\
\hline transmembrane transporter activity & 19 & 930 & $2.04 \%$ \\
\hline substrate-specific transporter activity & 10 & 865 & $1.16 \%$ \\
\hline binding & 156 & 10009 & $1.56 \%$ \\
\hline nucleotide binding & 25 & 2177 & $1.15 \%$ \\
\hline nucleic acid binding & 41 & 3939 & $1.04 \%$ \\
\hline protein binding & 31 & 2640 & $1.17 \%$ \\
\hline lipid binding & 7 & 267 & $2.62 \%$ \\
\hline oxygen binding & 12 & 231 & $5.19 \%$ \\
\hline carbohydrate binding & 3 & 153 & $1.96 \%$ \\
\hline ion binding & 46 & 2255 & $2.04 \%$ \\
\hline amine binding & 1 & 23 & $4.35 \%$ \\
\hline tetrapyrrole binding & 17 & 320 & $5.31 \%$ \\
\hline cofactor binding & 10 & 264 & $3.79 \%$ \\
\hline metal cluster binding & 3 & 40 & $7.50 \%$ \\
\hline electron carrier activity & 23 & 495 & $4.65 \%$ \\
\hline antioxidant activity & 4 & 126 & $3.17 \%$ \\
\hline peroxidase activity & 4 & 109 & $3.67 \%$ \\
\hline enzyme regulator activity & 9 & 342 & $2.63 \%$ \\
\hline enzyme inhibitor activity & 7 & 174 & $4.02 \%$ \\
\hline kinase regulator activity & 2 & 42 & $4.76 \%$ \\
\hline transcription regulator activity & 35 & 1885 & $1.86 \%$ \\
\hline two-component response regulator activity & 1 & 35 & $2.86 \%$ \\
\hline transcription factor activity & 29 & 1677 & $1.73 \%$ \\
\hline RNA polymerase II transcription factor activity & 1 & 34 & $2.94 \%$ \\
\hline transcription activator activity & 2 & 134 & $1.49 \%$ \\
\hline transcription repressor activity & 1 & 48 & $2.08 \%$ \\
\hline transcription initiation factor activity & 1 & 20 & $5.00 \%$ \\
\hline nutrient reservoir activity & 2 & 58 & $3.45 \%$ \\
\hline molecular transducer activity & 3 & 375 & $0.80 \%$ \\
\hline signal transducer activity & 3 & 375 & $0.80 \%$ \\
\hline
\end{tabular}




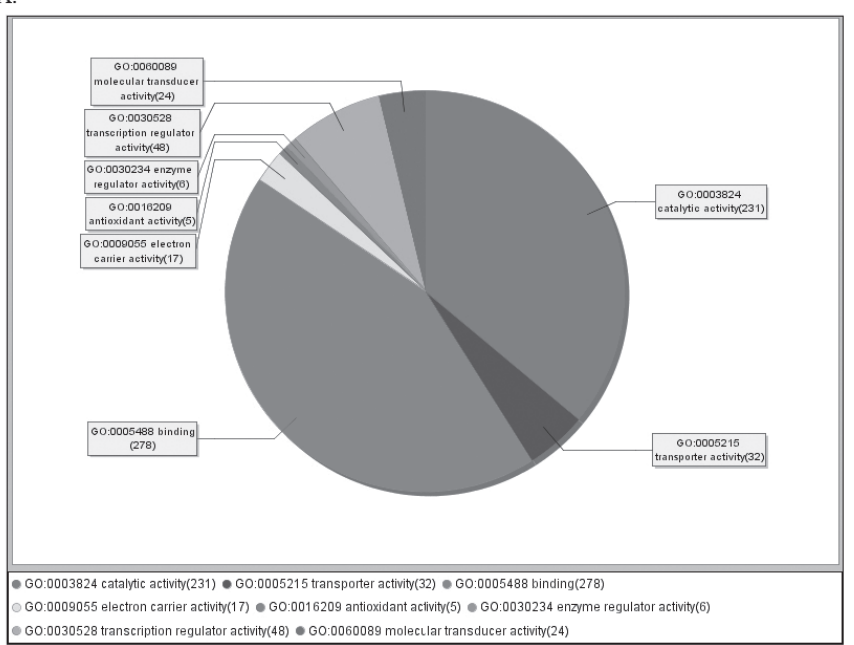

B.

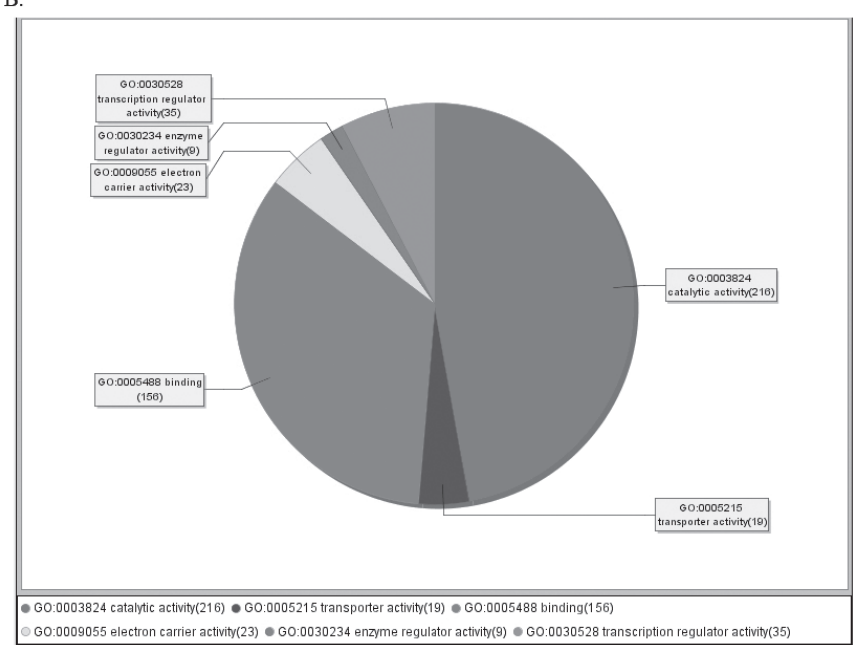

Fig. 4. Functional physiological categorisation of differentially expressed genes respond to $3 \mathrm{mM} \mathrm{BPA}$. A, up-regulated gene; B, down-regulated gene.

WRKY63, and WRKY75 were upregulated by 6.4-fold, 5.0-fold, and 4.0-fold, respectively, compared with corresponding controls. Transcription factors induced by BPA and their downstream target genes form a network to increase plant resistance to environmental stresses. Among BPA upregulated genes, 9 cytochrome P450 monooxygenase genes, including CYP714A1, CYP81F2, CYP710A1, CYP704A1, CYP71A15, CYP710A3, and CYP89A6, were upregulated by over 2.5-fold (Supplementary Table S2). The biological functions of cytochrome P450 monooxygenases are based on their ability to catalyze oxygen insertion into various compounds. Mammalian P450 proteins are critical for detoxification of PAHs and BPA (Raucy and Allen, 2001; Sasaki et al., 2005; Stiborova et al., 2003), and their catalytic functions are extremely diverse (Durst and Nelson, 1995). Thus, we speculate that upregulated WRKY genes induce the expression of cytochrome P450 genes under BPA stress by recognizing and binding special cis-elements in abiotic and biotic stress conditions.

In conclusion, we identified several genes encoding known or putative proteins that are induced under BPA stress conditions. Considering the continuous development of Arabidopsis functional genomics, the function of a protein identified through expression profiling analysis can be determined rapidly. These genes were classified according to their functions in response to BPA treatments. The potential involvement of several genes in BPA metabolism and plant defense was demonstrated by the induced expression of genes during stress treatments. The characterization of differential gene regulation in this study provides relevant data for selecting phytoremediation and phytosensing components. Further studies using other approaches, such as reverse genetics, are necessary to verify the functions of these genes in the metabolism of BPA and in plant stress responses.

\section{ACKNOWLEDGMENTS}

The research was sponsored by Shanghai RisingStar Program(14QB1403400); Shanghai Natural Science Foundation (13ZR1460600); Youth Talents Growth Plan of Shanghai Academy of Agricultural Sciences (20141-19); The Key Project Fund of the Shanghai Municipal Committee of Agriculture (No. 2011-1-8, zhongzi2013-8, zhongzi2014-2); International Scientific and Technological Cooperation (13440701700); Agriculture science technology achievement transformation fund (133919N1300); National Natural Science Foundation (31071486, 31300237,31200076 ) and the Key Project Fund of Shanghai Minhang Science and Technology Committee (2012MH059); Basic research in the field of science and technology project of Science and Technology Commission of Shanghai Municipality (14JC1403602).

\section{REFERENCES}

Ben-Jonathan, N. and Steinmetz, R. (1998): Xenoestrogens: the emerging story of bisphenol a. Trends Endocrinol. Metab., 9, 
Microarray analysis of genes responses to BPA

124-128.

Blokhina, O. and Fagerstedt, K.V. (2010): Oxidative metabolism, ROS and NO under oxygen deprivation. Plant Physiol. Biochem. 48, 359-373.

Boldogh, I., Bacsi, A., Choudhury, B.K., Dharajiya, N., Alam, R., Hazra, T.K., Mitra, S., Goldblum, R.M. and Sur, S. (2005): ROS generated by pollen NADPH oxidase provide a signal that augments antigen-induced allergic airway inflammation. J. Clin. Invest., 115, 2169-2179.

Brancolini, C. (2008): Inhibitors of the Ubiquitin-Proteasome System and the cell death machinery: How many pathways are activated? Curr. Mol. Pharmacol., 1, 24-37.

Coupe, S.A., Sinclair, B.K., Watson, L.M., Heyes, J.A. and Eason, J.R. (2003): Identification of dehydration-responsive cysteine proteases during post-harvest senescence of broccoli florets. J. Exp. Bot., 54, 1045-1056.

Dixit, P., Mukherjee, P.K., Sherkhane, P.D., Kale, S.P. and Eapen, S. (2011): Enhanced tolerance and remediation of anthracene by transgenic tobacco plants expressing a fungal glutathione transferase gene. J. Hazard Mater., 192, 270-276.

Durst, F. and Nelson, D.R. (1995): Diversity and evolution of plant P450 and P450-reductases. Drug Metabol. Drug Interact., 12, 189-206.

Fukuda, T., Uchida, H., Takashima, Y., Uwajima, T., Kawabata, T. and Suzuki, M. (2001): Degradation of bisphenol A by purified laccase from Trametes villosa. Biochem. Biophys. Res. Commun., 284, 704-706.

Hirano, T., Honda, Y., Watanabe, T. and Kuwahara, M. (2000): Degradation of bisphenol A by the lignin-degrading enzyme, manganese peroxidase, produced by the white-rot basidiomycete, Pleurotus ostreatus. Biosci. Biotechnol. Biochem., 64, 1958-1962.

Hu, A., Lv, M. and Yu, C.P. (2013): Draft Genome Sequence of the Bisphenol A-Degrading Bacterium Sphingobium sp. Strain YL23. Genome Announc., 1.

Kobayashi, M., Ohura, I., Kawakita, K., Yokota, N., Fujiwara, M., Shimamoto, K., Doke, N. and Yoshioka, H. (2007): Calcium-dependent protein kinases regulate the production of reactive oxygen species by potato NADPH oxidase. Plant Cell, 19, 10651080.

Krishnan, A.V., Stathis, P., Permuth, S.F., Tokes, L. and Feldman, D. (1993): Bisphenol-A: an estrogenic substance is released from polycarbonate flasks during autoclaving. Endocrinology, 132, 2279-2286.

Kwak, J.M., Mori, I.C., Pei, Z.M., Leonhardt, N., Torres, M.A., Dangl, J.L., Bloom, R.E., Bodde, S., Jones, J.D. and Schroeder, J.I. (2003): NADPH oxidase AtrbohD and AtrbohF genes function in ROS-dependent ABA signaling in Arabidopsis. EMBO J., 22, 2623-2633.

Laloi, C., Rayapuram, N., Chartier, Y., Grienenberger, J.M., Bonnard, G. and Meyer, Y. (2001): Identification and characterization of a mitochondrial thioredoxin system in plants. Proc. Natl. Acad. Sci. USA, 98, 14144-14149.

Li, J.M. and Shah, A.M. (2003): ROS generation by nonphagocytic NADPH oxidase: potential relevance in diabetic nephropathy. J. Am. Soc. Nephrol., 14, S221-226.

Lin, S.I., Chiang, S.F., Lin, W.Y., Chen, J.W., Tseng, C.Y., Wu, P.C. and Chiou, T.J. (2008): Regulatory network of microRNA399 and PHO2 by systemic signaling. Plant Physiol., 147, 732-746.

Lindholst, C., Pedersen, S.N. and Bjerregaard, P. (2001): Uptake, metabolism and excretion of bisphenol $\mathrm{A}$ in the rainbow trout (Oncorhynchus mykiss). Aquat. Toxicol., 55, 75-84.

Marrs, K.A. (1996): The Functions and Regulation of Glutathione S-Transferases in Plants. Annu. Rev. Plant Physiol. Plant Mol. Biol., 47, 127-158.

Mittler, R., Vanderauwera, S., Gollery, M. and Van Breusegem, F. (2004): Reactive oxygen gene network of plants. Trends Plant Sci., 9, 490-498.

Nakajima, N., Ohshima, Y., Serizawa, S., Kouda, T., Edmonds, J.S., Shiraishi, F., Aono, M., Kubo, A., Tamaoki, M., Saji, H. and Morita, M. (2002): Processing of bisphenol A by plant tissues: glucosylation by cultured BY-2 cells and glucosylation/translocation by plants of Nicotiana tabacum. Plant Cell Physiol., 43, 1036-1042.

Ooe, H., Taira, T., Iguchi-Ariga, S.M. and Ariga, H. (2005): Induction of reactive oxygen species by bisphenol A and abrogation of bisphenol A-induced cell injury by DJ-1. Toxicol. Sci., 88, 114126.

Owens, I.S., Basu, N.K. and Banerjee, R. (2005): UDP-glucuronosyltransferases: gene structures of UGT1 and UGT2 families. Methods Enzymol., 400, 1-22.

Raucy, J.L. and Allen, S.W. (2001): Recent advances in P450 research. Pharmacogenomics. J., 1, 178-186.

Sasaki, M., Akahira, A., Oshiman, K., Tsuchido, T. and Matsumura, Y. (2005): Purification of cytochrome P450 and ferredoxin, involved in bisphenol A degradation, from Sphingomonas sp. strain AO1. Appl. Environ. Microbiol., 71, 8024-8030.

Stiborova, M., Sucha, V., Miksanova, M., Paca, J.Jr. and Paca, J. (2003): Hydroxylation of phenol to catechol by Candida tropicalis: involvement of cytochrome P450. Gen. Physiol. Biophys., 22, $167-179$.

Tsutsumi, Y., Haneda, T. and Nishida, T. (2001): Removal of estrogenic activities of bisphenol $\mathrm{A}$ and nonylphenol by oxidative enzymes from lignin-degrading basidiomycetes. Chemosphere, 42, 271-276.

Vranova, E., Atichartpongkul, S., Villarroel, R., Van Montagu, M., Inze, D. and Van Camp, W. (2002): Comprehensive analysis of gene expression in Nicotiana tabacum leaves acclimated to oxidative stress. Proc. Natl. Acad. Sci. USA, 99, 10870-10875.

Wagner, U., Edwards, R., Dixon, D.P. and Mauch, F. (2002): Probing the diversity of the Arabidopsis glutathione S-transferase gene family. Plant Mol. Biol., 49, 515-532.

Welshons, W.V., Nagel, S.C. and vom Saal, F.S. (2006): Large effects from small exposures. III. Endocrine mechanisms mediating effects of bisphenol A at levels of human exposure. Endocrinology, 147, S56-69.

Ye, X., Pierik, F.H., Angerer, J., Meltzer, H.M., Jaddoe, V.W., Tiemeier, H., Hoppin, J.A. and Longnecker, M.P. (2009): Levels of metabolites of organophosphate pesticides, phthalates, and bisphenol A in pooled urine specimens from pregnant women participating in the Norwegian Mother and Child Cohort Study (MoBa). Int. J. Hyg. Environ. Health, 212, 481-491. 